\title{
Analisis Sifat Mekanik dan Tofografi Permukaan Bata Merah di Kabupaten Bangka dengan Menggunakan Metode RSM
}

\author{
Yuliyanto, Eko Yudo, Zakdi Sirwansyah Suzen \\ Jurusan Teknik Mesin, Politeknik Manufaktur Negeri Bangka Belitung \\ Email: belzanyuliyanto@yahoo.com
}

\begin{abstract}
Informasi ABSTRAK
Artikel:

Received:

2 Januari 2019

Accepted:

4 Maret 2019

Available

1 Desember

2019

Pemanfaatan batu bata dalam konstruksi baik non-struktur ataupun struktur perlu adanya peningkatan produk yang dihasilkan, baik dengan cara meningkatkan kualitas bahan berdasarkan SNI 15-2094-2000 yang menjelaskan tentang bata merah. Tujuan penelitian ini untuk menganalisa pengaruh Variabel Bebas yaitu Perbandingan suhu pemanasan dengan waktu proses 12 jam, 24 Jam dan 36 jam, dengan suhu $300^{\circ} \mathrm{C}, 500^{\circ} \mathrm{C}$ dan $700^{\circ} \mathrm{C}$ dan persentase campuran pasir $5 \%, 10 \%$ dan $15 \%$. Perbandingan ketiga variable bebas tersebut akan dilihat berapa nilai Optimum dari uji Impak dan bagaimana patahan yang terjadi dilihat dengan SEM. Hasil menunjukan nilai impak terkecil $264 \mathrm{kj} / \mathrm{m} 2$, dan nilai terbesar sebesar $164 \mathrm{kj} / \mathrm{m} 2$. nilai $\mathrm{F}$ hitung $F M o d e /=33,29$ yang didapat pada tingkat signifikan sebesar 0,01 atau $1 \%$ dan nilai $p(0,0002)$ memberikan nilai signifikan terhadap model yang ada. Sedangkan Lack of Fit yang terjadi sebesar 0,000199 dan tidak memberikan pengaruh (not signifikan) sehingga persamaan regresi mode matematika cubic model yang digunakan dapat diterima. Berdasarkan data interaksi dan permukaan respon terhadap kekuatan impak maka pengaruh waktu pemanasan, suhu pemanasan dan persentase pasir sangan besar sekali. Intinya jika suhu dan waktu pemanasan semakin besar maka hasil uji impak semakin besar
\end{abstract}

\begin{tabular}{l} 
Kata Kunci \\
\hline \\
Bata Merah \\
Uji Impak \\
Pemanasan \\
Waktu \\
Pasir
\end{tabular}

\begin{abstract}
The use of bricks in both non-structural and structural construction needs to be an increase in the product produced, either by improving the quality of materials based on SNI 15-2094-2000 which explains the red brick. The purpose of this study was to analyze the effect of the Independent Variable, namely the Comparison of heating temperatures with a processing time of 12 hours, 24 hours and 36 hours, with temperatures of 3000 C, 5000C and $7000 \mathrm{C}$ and the percentage of sand mixture of 5\%,10\% and $15 \%$. Comparison of the three independent variables will be seen what is the Optimum value of the Impact test and how the fracture that occurs is seen with SEM. The results show the smallest impact value of $264 \mathrm{kj} / \mathrm{m2}$, and the largest value of $164 \mathrm{kj} /$ m2. the calculated $F$ value of FModel $=33.29$ obtained at a significant level of 0.01 or $1 \%$ and the $p$ value (0.0002) gives a significant value to the existing model. Whereas the Lack of Fit that occurs is 0.000199 and does not have an effect (not significant) so that the cubic mathematical model regression equation used can be accepted. Based on the interaction data and surface response to the impact strength, the effect of heating time, heating temperature and percentage of sand is very large. The point is that if the temperature and the heating time get bigger the impact test results will be even greater
\end{abstract}




\section{Pendahuluan}

Latar Belakang Batu bata merupakan bahan bangunan yang sering digunakan untuk aplikasi teknik sipil seperti dinding perumahan. Memilih batu bata sebagai bahan pembuat dinding memang cukup beralasan. Hal ini dikarenakan batu bata memiliki keunggulan yaitu, bahan utama batu bata yang merupakan tanah liat mudah didapat dengan persediaan yang cukup, sehingga menyebabkan harga batu bata cukup murah. Selain karena bahan baku yang mudah didapat, batu bata juga mudah dibuat [4]. Hanya membutuhkan alat-alat sederhana dan modal yang kecil sehingga banyak masyarakat yang dapat membuat dan persediaan batu bata menjadi mudah diperoleh. Warna oranye yang menjadi ciri khas batu bata menjadi daya tarik sendir. produk batu bata merah metode tradisional masih banyak terdapat batu bata merah yang mudah retak, dikarnakan kontruksi tanah setiap daerah berbeda-beda. Sehingga produk yang retak atau pecah tidak dapat di pasarkan, untuk itu perlu ditingkatkan kualitas produks batu bata merah metode tradisional dengan memanfaatkan material limbah abu serat sabut kelapa dan abu serbuk gergaji.Persentase rasio campuran eksperimen yang digunakan yaitu 2,5\%,5\%, dan $10 \%$ dari berat tanah liat yang digunakan, dari persentase tersebut juga dapat menurunkan biaya produksi (Low Cost Production)[1].

Pemilik rumah adakalanya sengaja tidak menutup batu bata dengan semen dan cat, sebaliknya batu bata dibiarkan terekspos sehingga memberikan kesan alami pada rumah. Batu bata tahan 2 Untuk dapat memenuhi kebutuhan batu bata seiring dengan peningkatan jumlah dan laju perkembangan penduduk, produksi batu bata pun harus ditingkatkan, bukan hanya dalam segi jumlah tapi juga mutu [8]. Adapun kualitas batu bata merah yang tersedia kebanyakan mudah retak dan hancur akibat kurang kualitas batu bata yang dihasilkan [1]. Maka dalam pembuatan batu bata perlu adanya peningkatan mutu yang dihasilkan secara efektif. Untuk mengurangi dampak negatif yang terjadi tersebut maka di berikan suatu solusi. Seiring perkembangan tekhnologi saat ini, mulai banyak melakukan inovas inovasi yang membantu memperbaiki mutu dan kualitas batu bata yang dihasilkan. pembuatan batu bata pasca pembakaran dengan menggunakan campuran zeolit memenuhi Standar Nasional Indonesia (SNI) batu bata untuk material bangunan. Secara umum penambahan bahan zeolit pada tanah mengurangi nilai berat jenis tanah campuran. Untuk nilai kuat tekan batu bata tanpa pembakaran dan dengan proses pembakaran paling baik ditunjukkan pada penambahan kadar campuran $10 \%-12 \%$ [2].

Batu bata dikatakan bermutu dan berkualitas baik apabila (standar Mutu, 2000):

a. Batu bata harus bebas dari retak atau cacat, dan dari batu dan benjolan apapun.

b. Batu bata harus seragam dalam ukuran, dengan sudut tajam dan tepi yang rata.

c. Permukaan harus benar dalam bentuk persegi satu sama lain untuk menjamin kerapian pekerjaan.

d. Mempunyai ukuran, kuat tekan dan daya serap air yang dipersyaratkan.

Batu bata dalam proses pembuatan bukan hanya kegiatan mencetak tanah, mengeringkan dan membakar, akan tetapi diperlukan campuran agar menjadi batu bata yang kualitas sesuai dengan yang diinginkan [5]. Pemberian campuran ini dimaksudkan agar kualitas bahan utama pembuatan batu bata yang merupakan tanah liat mempunyai kuat tekan yang lebih baik. Pada penelitian 3 ini sebagai campurann adalah menggunakan larutan ISS 2500 (Ionic Soil Stabilizer). Larutan ini dipilih karena merupakan bahan additive yang sangat baik untuk meningkatkan kondisi tanah yang jelek dalam stabilisasi tanah secara elektro-kimiawi. Tanah liat atau tanah lempung dapat distabilisasi dengan mencampur zat additive larutan 
ISS 2500 (Ionic Soil Stabilizer) [6] [9]. Batu-bata berbahan tambahan serbuk gergaji dengan rasio berat antara serbuk gergaji, tanah liat, dan kaolin 20:70:90, 40:70:90 dan 60:70:90 gram, semuanya berdaya serap $>20 \%$, belum memenuhi standar kualitas berdasarkan SNI 15-2094-2000, walaupun kualitas fisik batu-bata tersebut secara keseluruhan mempunyai struktur yang sangat ringan [3].

Dalam proses pembuatan batu bata jenis ini dilakukan beberapa tahapan setelah pencetakan yaitu pengeringan dan pembakaran, dimana batu bata ini sudah dicampurkan terlebih dahulu dengan zat additive yaitu larutan ISS 2500 . Setelah pembakaran dilakukan pengujian tarik untuk mengetahui kekuatan batu bata pasca pembakaran dan dkarakteristik material akibat dari proses pemanasan dengan perbandingan suhu, lama proses pemanasan dan dimensi ukuran batu merah. Diharapkan penelitian yang dilakukan kolaborasi pemanasan dan dimensi ukuran ini dapat menghasilkan batu bata yang baik kualitasnya sehingga hasil yang di dapat dari penelitian ini dapat bermanfaat bagi masyarakat Bangka Belitung pada umumnya dan Rakyat Indonesia pada umumnya.

\section{METODOLOGI PENELITIAN}

Pelaksanaan penelitian dilakukan dengan beberapa tahap yang digunakan sesuai pedoman penelitian, langkah awal dimulai dari studi-studi literatur yang didapat dari jurnal ilmiah. internet, handbook, text book, manual book. Selanjutnya data-data studi literature dipelajari dan dijadikan referensi untuk melakukan penelitian.

\subsection{Bahan dan Alat Penelitian}

Bahan yang digunakan adalah dalam penelitian ini adalah sebagai berikut: Tanah kaulin sebagai sumber utama, pasir sebagai pencampur dan pemisah agar tidak lengket, dan cetakan sebagai alat cetak baru bata. Gambar bahan dan proses cetak pada Gambar 1.
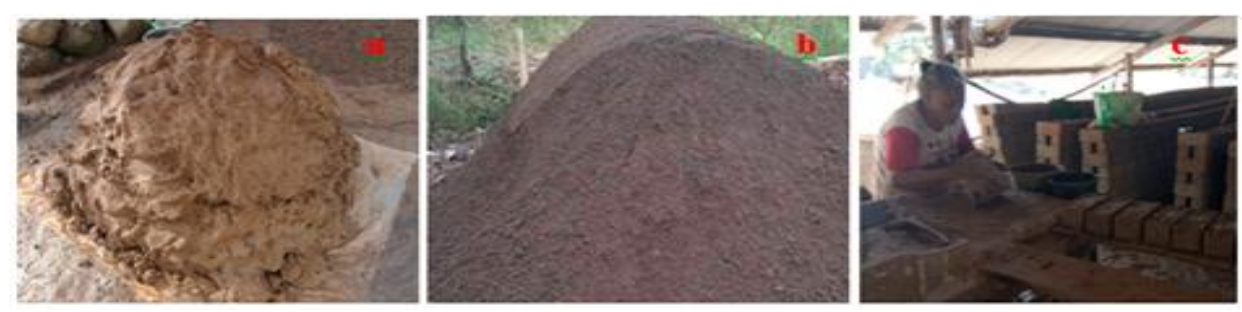

Gambar 1(a) Tanah Liat/kaulin, (b) Pasir halus dan (C) Proses pembentukan bata merah

Adapun peralatan yang digunakan dalam proses penelitian ini adalah oven listrik dengan kemampuan suhu $1300{ }^{\circ} \mathrm{C}$.dan timbangan untuk melihat berat awal dan berat setelah di lakukan pemanasan. Adapun gambar peralatan dapat dilihat pada Gambar 2 

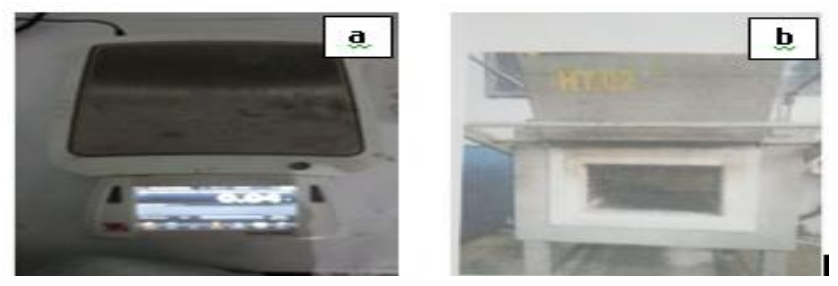

Gambar 2(a) Timbangan Digital, (b) Oven Listrik

\subsection{Peralatan Pengujian}

Alat uji yang digunakan adalah uji impak. Uji impak ini digunakan untuk mendapatkan sifat mekanik yaitu kekuatan impak dari batu merah yang dilakukan proses pengovenan. Tempat pengujian di laboratorium material Jurusan Teknik Mesin Politeknik Manufaktur Negeri Bangka Belitung.. Alat Uji Scanning Electron Microscope (SEM) yang digunakan adalah Inspect S50 buatan FEI Company. Alat ini untuk mengetahui perubahan struktur yang terjadi dari hasil pengujian.

\subsection{Analisa}

Analisa dilakukan dengan mengunakan Metode Permukaan Respon (RSM), dimana akan dilihat pengaruh Variabel Bebas yaitu Perbandingan suhu pemanasan dengan waktu proses 12 jam, 24 Jam dan 36 jam, dengan suhu $300^{\circ} \mathrm{C}, 500^{\circ} \mathrm{C}$ dan $700^{\circ} \mathrm{C}$ dan persentase campuran pasir $5 \%, 10 \%$ dan $15 \%$. Dari perbandingan ketiga variable bebas tersebut akan dilihat berapa nilai Optimum dari uji Impak dan bagaimana patahan yang terjadi dilihat dengan Scanning Elekron Miskroscop (SEM).

\section{HASIL}

\subsection{Pengujian Impak}

\subsubsection{Hasil Pengujian Impak}

Pengujian Impak dilakukan untuk mengetahui pengaruh Variabel Bebas Perbandingan suhu pemanasan, waktu proses $12 \mathrm{jam}, 24 \mathrm{Jam}$ dan $36 \mathrm{jam}$, dengan suhu $300^{\circ} \mathrm{C}, 500^{\circ} \mathrm{C}$ dan $700^{\circ} \mathrm{C}$. Data hasil pengujian selanjutnya diolah sehingga diperoleh kesimpulan dan menghasilkan nilai yang optimum. Pengolahan data dilakukan dengan Metode Respon surface Metodelogi. Berikut Hasil Pengujian Impak berdasarkan RSM. (Tabel 1)

Tabel 1. Hasil Pengujian Impak

\begin{tabular}{cccccc} 
No & RUN & Suhu Pemanasan & Waktu Pemanasan & Persentase Pasir & Hasil Uji Impak \\
\cline { 3 - 6 } & & ${ }^{\circ} \mathbf{C}$ & Jam & $\%$ & $\mathbf{K j} / \mathbf{m}^{\mathbf{2}}$ \\
\hline 1 & 20 & 300 & 24 & 5 & 257 \\
\hline 2 & 11 & 700 & 24 & 5 & 210 \\
\hline 3 & 3 & 300 & 48 & 5 & 254 \\
\hline 4 & 1 & 700 & 48 & 5 & 213 \\
\hline 5 & 13 & 300 & 24 & 15 & 256 \\
\hline 6 & 15 & 700 & 24 & 15 & 254 \\
\hline
\end{tabular}




\begin{tabular}{ccccccc}
7 & 10 & 300 & 48 & 15 & 210 \\
\hline 8 & 2 & 700 & 48 & 15 & 221 \\
\hline 9 & 5 & 163.64 & 36 & 10 & 264 \\
\hline 10 & 6 & 836.36 & 36 & 10 & 154 \\
\hline 11 & 16 & 500 & 15.82 & 10 & 232 \\
\hline 12 & 19 & 500 & 56.18 & 10 & 257 \\
\hline 13 & 14 & 500 & 36 & 1.59 & 249 \\
\hline 14 & 8 & 500 & 36 & 18.41 & 234 \\
\hline 15 & 18 & 500 & 36 & 10 & 242 \\
\hline 16 & 12 & 500 & 36 & 10 & 240 \\
\hline 17 & 4 & 500 & 36 & 10 & 232 \\
\hline 18 & 9 & 500 & 36 & 10 & 232 \\
\hline 19 & 17 & 500 & 36 & 10 & 240 \\
\hline 20 & 7 & 500 & 36 & 10 & \\
\hline
\end{tabular}

Berdasarkan hasil pengujian impak dengan menggunakan metode respon surface maka didapat 20 kali percobaan dengan pengulangan 6 kali di tengah batu bata merah. Hasil menunjukan bahwa nilai impak terkecil pada percobaan no 9 yaitu sebesar $264 \mathrm{kj} / \mathrm{m}^{2}$ dengan parameter suhu pemanasan $163,62{ }^{\circ} \mathrm{C}$, waktu $36 \mathrm{Jam}$ dan persentase pasir $10 \%$. dan nilai yang terbesar di percobaan no 10 sebesar $164 \mathrm{kj} / \mathrm{m}^{2}$ dengan parameter suhu pemanasan $836.36{ }^{\circ} \mathrm{C}$, waktu $36 \mathrm{Jam}$ dan persentase pasir $10 \%$. Dapat ditarik garis besar bahwa pengaruh temperatur pemanasan sangat berpengaruh sekali.

\subsubsection{Anaalisis Variansi Kekuatan Impak $\left(\mathrm{Kj} / \mathrm{m}^{2}\right)$}

Hasil Pengujian Impak tersebut selanjutnya dilakukan Analisis Varian (ANOVA) untuk menyelidiki hubungan antara parameter Respon dengan 1 (satu) atau beberapa Variabel. Berikut hasil Analisis Varian pada pengujian Impak (Tabel 2)

Tabel 2. ANOVA untuk Respon Kekuatan Impak

\begin{tabular}{|c|c|c|c|c|c|}
\hline Response & 1 & Pengujian I & npak & & \\
\hline Transform: & Natural log & Constant: & 0 & & \\
\hline \multicolumn{6}{|c|}{ ANOVA for Response Surface Cubic Model (Aliased) } \\
\hline \multicolumn{6}{|c|}{ Analysis of variance table [Partial sum of squares - Type III] } \\
\hline & Sum of & & Mean & $\mathrm{F}$ & p-value \\
\hline Source & Squares & df & Square & Value & Prob > F \\
\hline Model & 0.27 & 13 & 0.021 & 33.29 & 0.0002 significant \\
\hline A-Suhu Pemenasan & 0.15 & 1 & 0.15 & 235.34 & $<0.0001$ \\
\hline B-Waktu Pemanasan & $5.24 \mathrm{E}-03$ & 1 & $5.24 \mathrm{E}-03$ & 8.48 & 0.0269 \\
\hline C-Persentase Pasir & $1.93 \mathrm{E}-03$ & 1 & $1.93 \mathrm{E}-03$ & 3.13 & 0.1274 \\
\hline$A B$ & 8.99E-04 & 1 & 8.99E-04 & 1.46 & 0.2728 \\
\hline$A C$ & 0.022 & 1 & 0.022 & 35.93 & 0.001 \\
\hline $\mathrm{BC}$ & 0.014 & 1 & 0.014 & 23.37 & 0.0029 \\
\hline$A^{\wedge} 2$ & 0.04 & 1 & 0.04 & 64.5 & 0.0002 \\
\hline $\mathrm{B}^{\wedge} 2$ & 3.30E-03 & 1 & 3.30E-03 & 5.35 & 0.0601 \\
\hline
\end{tabular}


Analisis Sifat Mekanik dan Tofografi Permukaan Bata Merah di Kabupaten Bangka dengan Menggunakan Metode RSM

\begin{tabular}{|c|c|c|c|c|c|}
\hline $\mathrm{C}^{\wedge} 2$ & $1.76 \mathrm{E}-03$ & 1 & $1.76 \mathrm{E}-03$ & 2.85 & 0.1421 \\
\hline$A B C$ & $1.36 \mathrm{E}-04$ & 1 & $1.36 \mathrm{E}-04$ & 0.22 & 0.6555 \\
\hline$A^{\wedge} 2 B$ & 0.017 & 1 & 0.017 & 28.04 & 0.0018 \\
\hline$A^{\wedge} 2 C$ & $1.69 \mathrm{E}-03$ & 1 & 1.69E-03 & 2.74 & 0.1489 \\
\hline$A B^{\wedge} 2$ & 0.046 & 1 & 0.046 & 75.25 & 0.0001 \\
\hline $\mathrm{AC}^{\wedge} 2$ & 0 & 0 & & & \\
\hline $\mathrm{B}^{\wedge} 2 \mathrm{C}$ & 0 & 0 & & & \\
\hline $\mathrm{BC}^{\wedge} 2$ & 0 & 0 & & & \\
\hline$A^{\wedge} 3$ & 0 & 0 & & & \\
\hline $\mathrm{B}^{\wedge} 3$ & 0 & 0 & & & \\
\hline $\mathrm{C}^{\wedge} 3$ & 0 & 0 & & & \\
\hline Residual & $3.70 \mathrm{E}-03$ & 6 & $6.17 \mathrm{E}-04$ & & \\
\hline Lack of Fit & $1.99 \mathrm{E}-03$ & 1 & 1.99E-03 & 5.83 & 0.0605 not significant \\
\hline Pure Error & $1.71 \mathrm{E}-03$ & 5 & $3.42 \mathrm{E}-04$ & & \\
\hline Cor Total & 0.27 & 19 & & & \\
\hline
\end{tabular}

Berdasarkan Tabel 2 terlihat nilai $\mathrm{F}$ hitung FModel $=33,29$ yang didapat pada tingkat signifikan sebesar 0,01 atau $1 \%$ dan nilai $p(0,0002)$ memberikan nilai signifikan terhadap model yang ada. Sedangkan Lack of Fit yang terjadi sebesar 0,000199 dan tidak memberikan pengaruh (not signifikan) sehingga persamaan regresi mode matematika dengan bentuk cubic model yang digunakan dapat diterima.

\subsubsection{Permukan Respon kekuatan Impak}

Grafik Interaksi untuk respon Kekuatan impak yang didapat dengan menggunakan bantuan perangkat lunak Disign Expert 9.0 dapat dilihat pada Gambar 4, dan Gambar 5 dan Gambar 6 berikut: 
Yuliyanto, Eko Yudo, Zald Sirwansyah Suzen

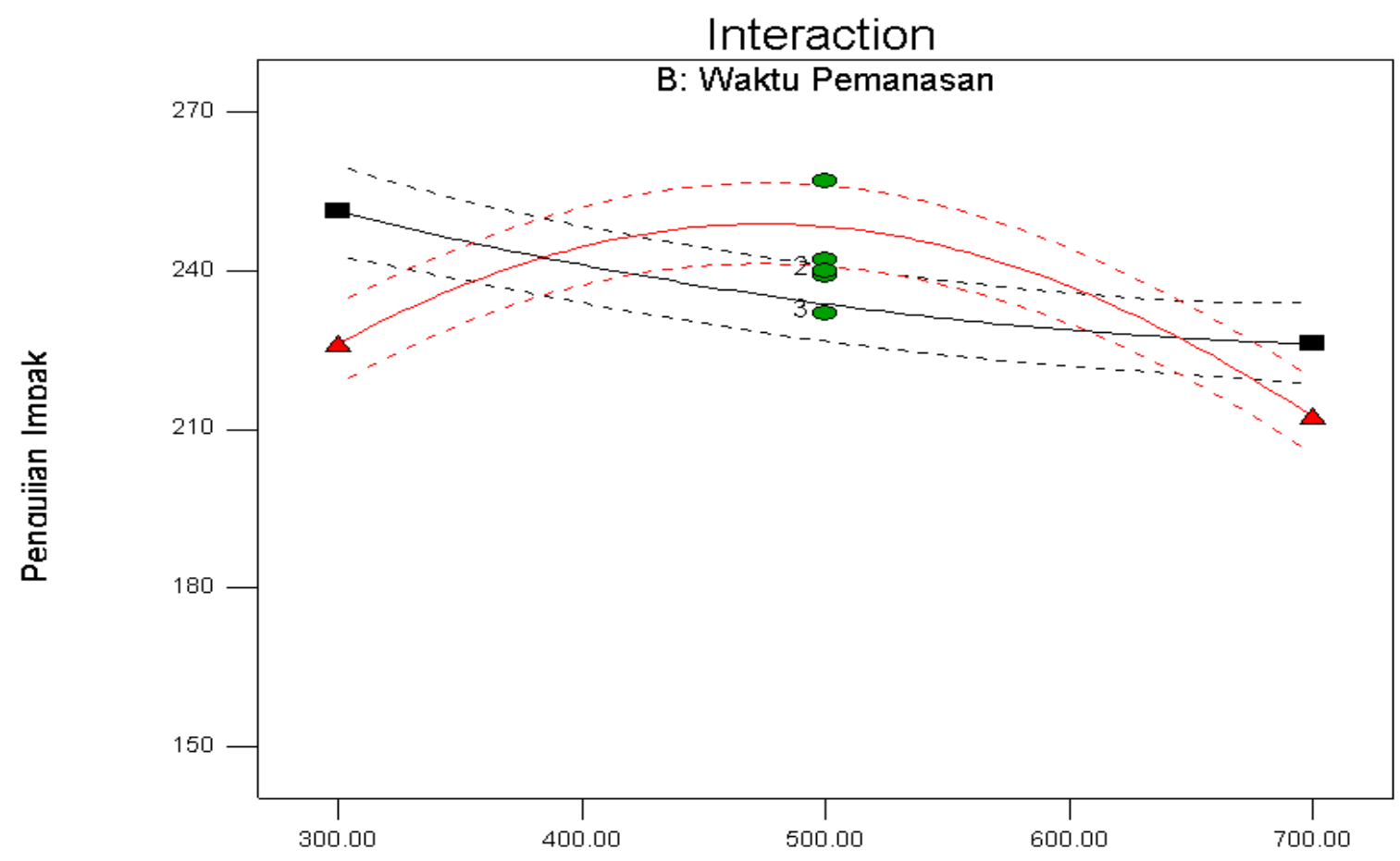

A: Suhu Pemenasan

Gambar 4. Interaksi Pengujian Impak terhadap Waktu Pemanasan vs Suhu Pemanasan

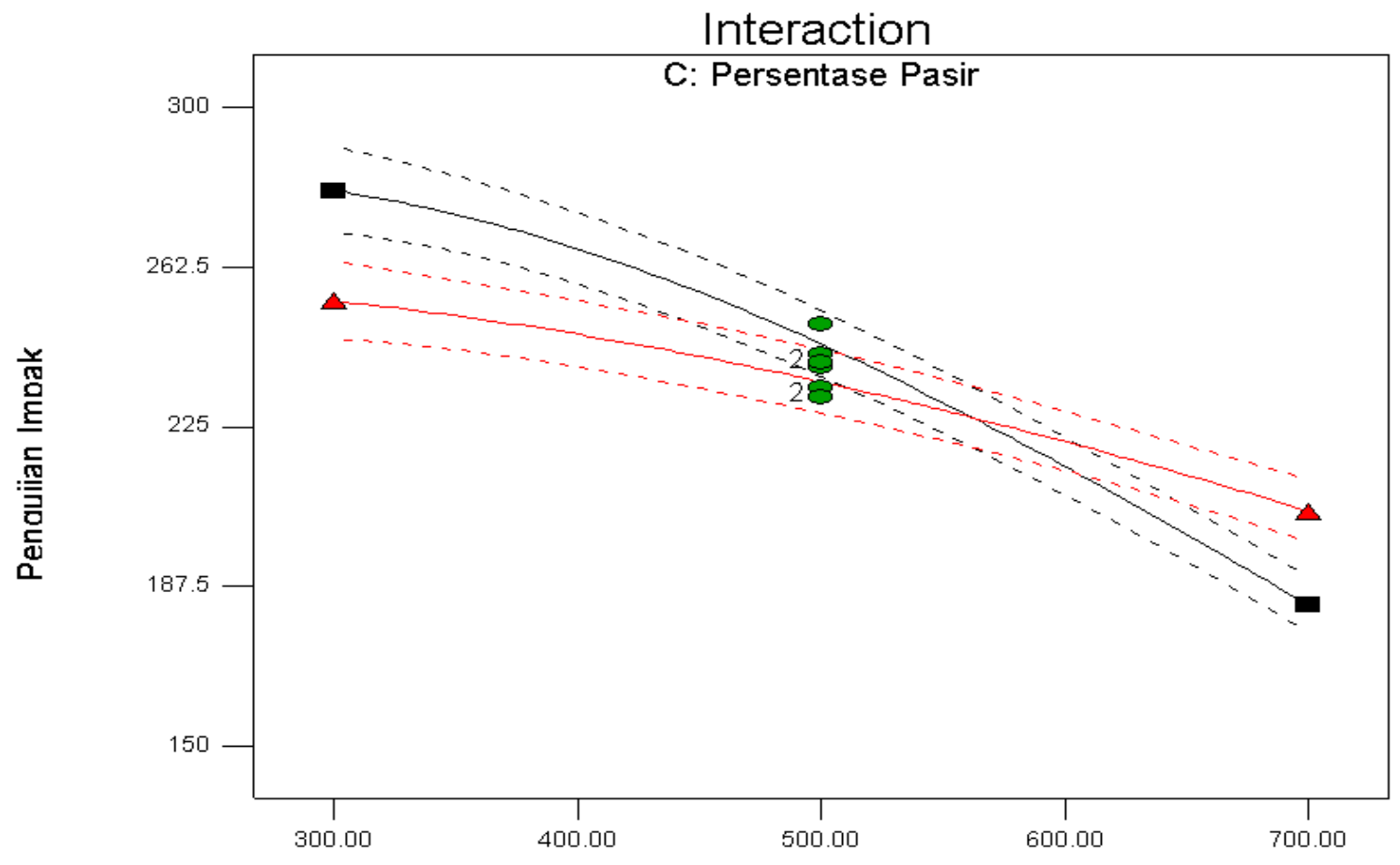

A: Suhu Pemenasan

Gambar 5. Interaksi Pengujian Impak terhadap Persentase Pasir vs Suhu Pemanasan 
Analisis Sifat Mekanik dan Tofografi Permukaan Bata Merah di Kabupaten Bangka dengan Menggunakan Metode RSM

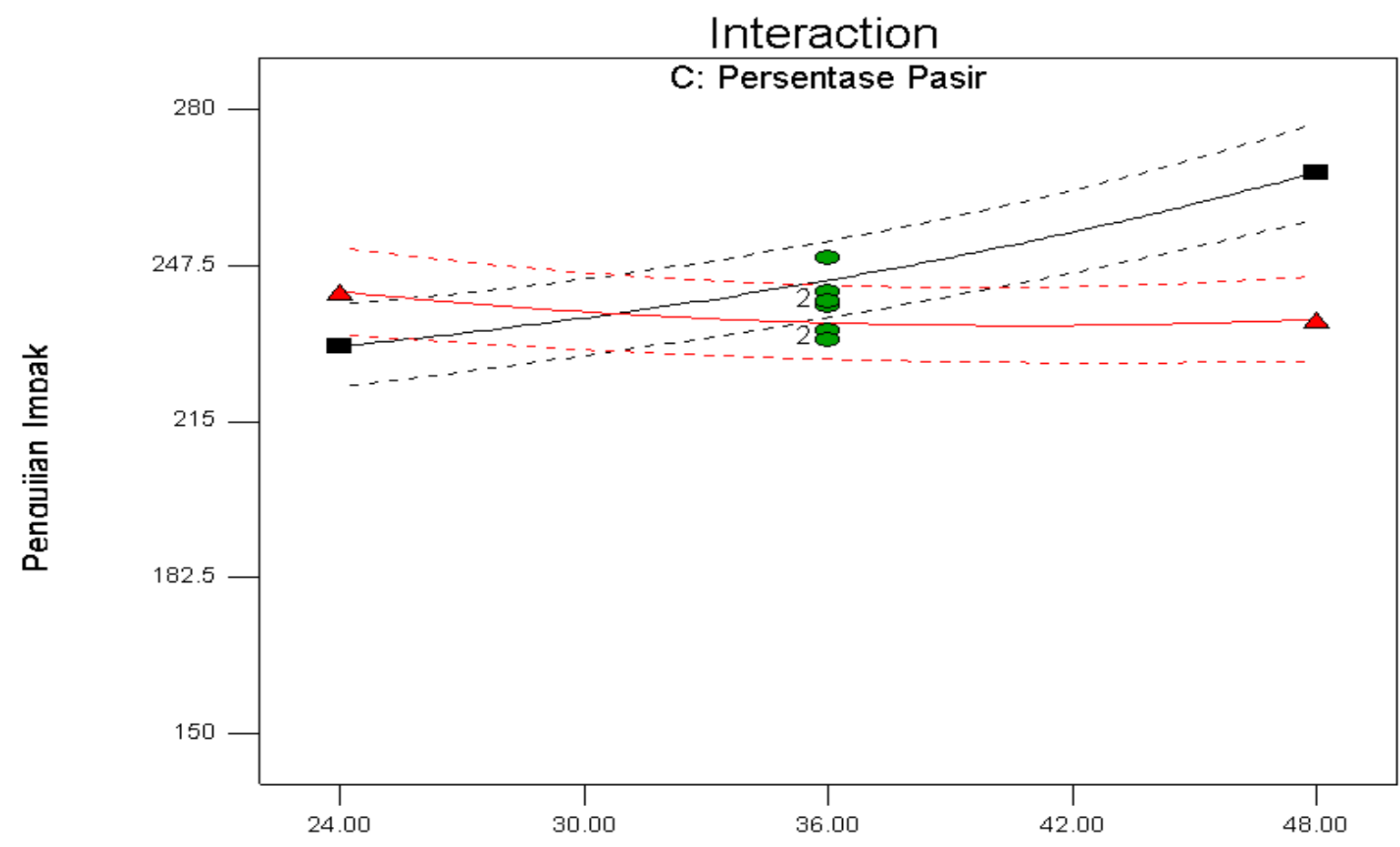

B: Waktu Pemanasan

Gambar 6. Interaksi Pengujian Impak terhadap Waktu Pemanasan vs Persentase Pasir

Dari Gambar 4, Gambar 5 dan Gambar 6 Interaksi antara ketiga variabel bebas sangat besar sekali terhadap Variabel uji impak. Dengan adanya pengujian pengulangan sebanyak 6 (enam) kali hasil uji impak akan lebih optimal. Untuk lebih jelasnya akan dibahan pada gambar 3 (tiga)D berdasarkan menggunakan metode Respon Surface Metodelogi Pada Gambar 7, Gambar 8 dan gambar 9 berikut.

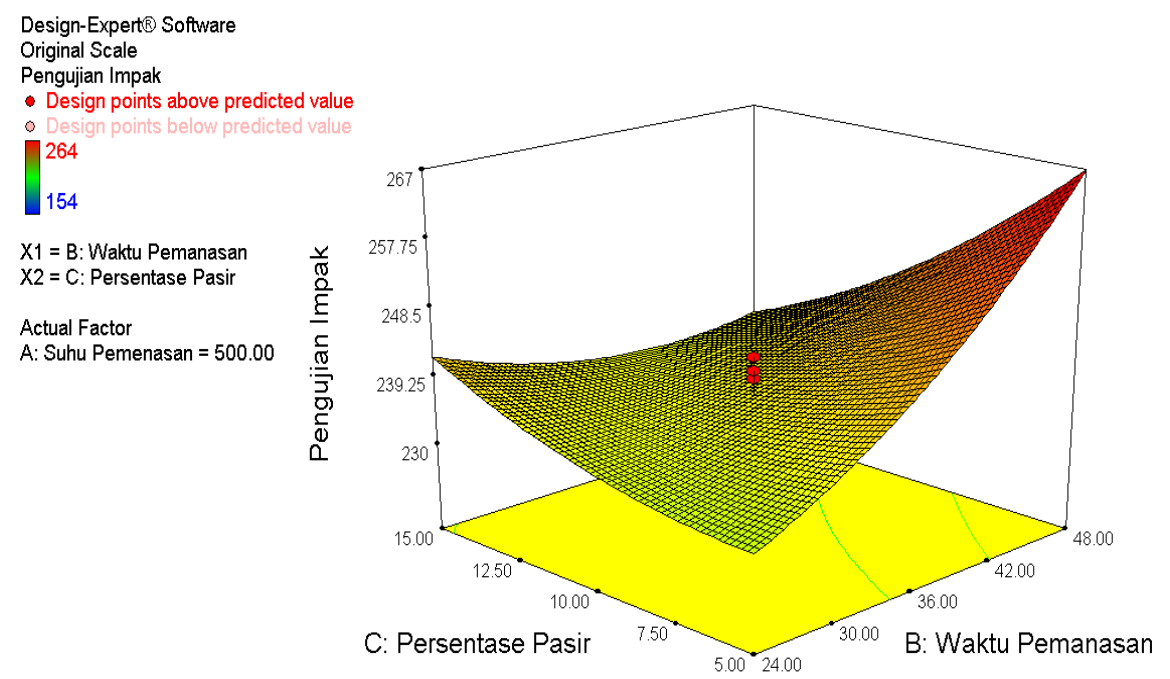

Gambar 7. Permukaan Respon Model Cubic Kekuatan Impak vs Persentase Pasir dan waktu Pemanasan 


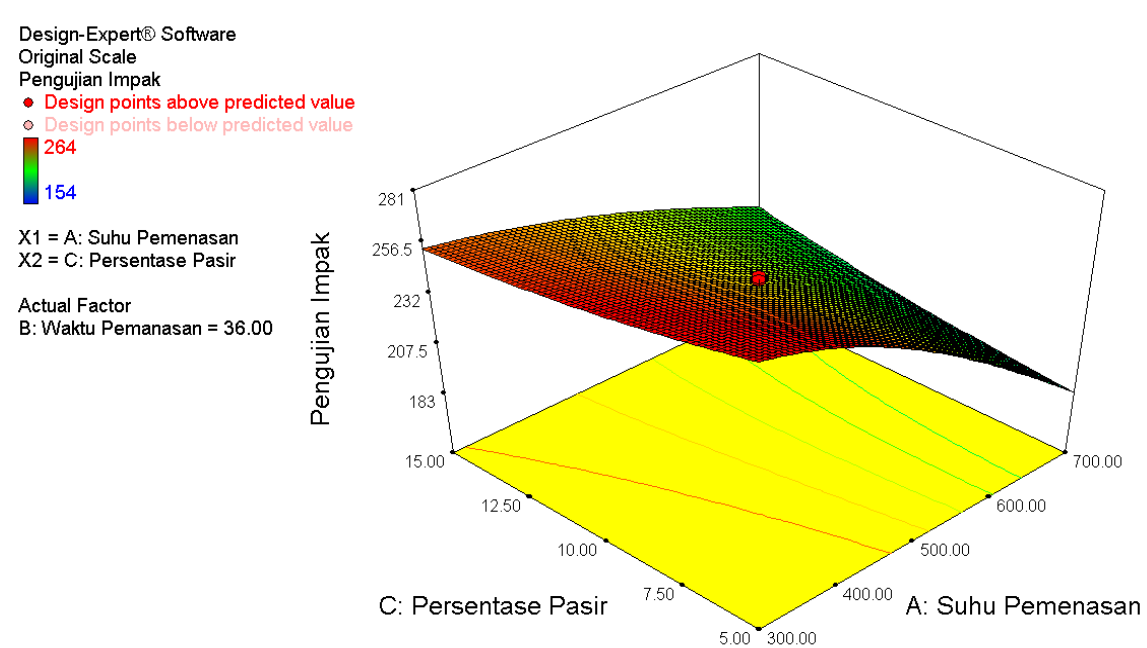

Gambar 8. Permukaan Respon Model Cubic Kekuatan Impak vs Persentase Pasir dan Suhu Pemanasan

Dari Gambar 7 dan Gambar 8 permukaan respon persentase pasir, suhu pemanasan dan waktu pemanasan sangat besar pengaruhnya terhadap kekuatan Impak. Kalau pada Gambar 7 Semakin banyak persentase pasir maka hasil pengujian impak semakin besar. Sedangkan untuk waktu pemanasan semakin tinggi maka nilai uji impaknya semakin besar pula. Sedangkan pada Gambar 8 pengaruh tingginya persentase pasir terhadap kekuatan impak maka hasil pengujiannya semakin kecil sedangkan suhu pemanasan semakin besar maka nilai kekuatan impak semakin kecil.

Berdasarkan data interaksi dan permukaan respon terhadap kekuatan impak maka pengaruh waktu pemanasan, suhu pemanasan dan persentase pasir sangan besar sekali. Intinya jika suhu dan waktu pemanasan semakin besar maka hasil uji impak semakin besar.

\subsubsection{Pengujian Scanning Electron Miscroscope (SEM)}

Pengujian SEM menggunakan Scanning Electron Microscope (SEM) Inspect S50. Pada pengujian SEM dilakukan pembesaran 200x dengan melihat perbedaan nilai uji Tarik tertinggi dan terendah. Hasil SEM dapat dilihat pada Gambar 9 sebagai berikut:
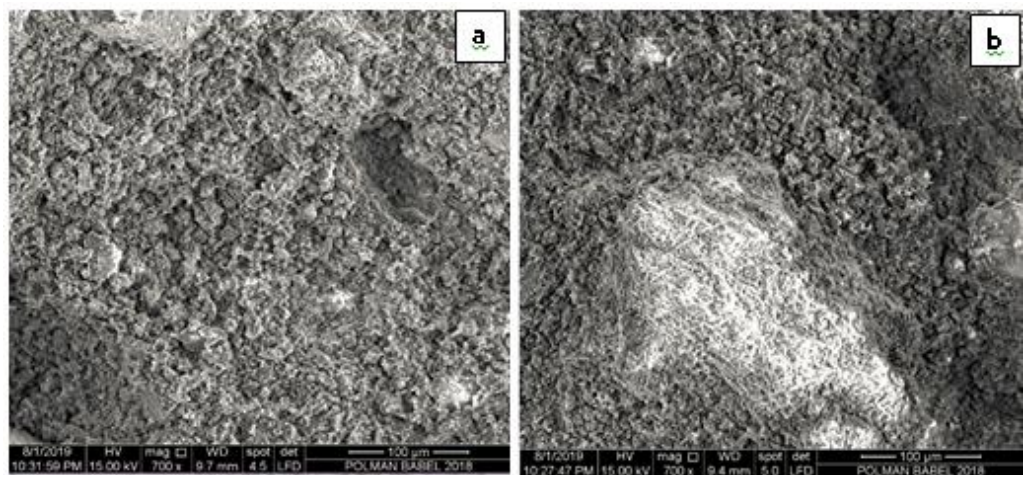

Gambar 9(a). Hasil SEM dengan nilai uji impak terbesar dan (b). Hasil SEM dengan nilai uji impak terkecil.

Berdasarkan hasil SEM diatas untuk Gambar 9(b) menunjukan ada beberapa bagian yang masih belum sempurna proses pemanasannya sehingga ada bagian tersebut yang menggumpal. Sedangkan Gambar 9(a) Proses pemanasan telah sempurna sehingga tidak 
Analisis Sifat Mekanik dan Tofografi Permukaan Bata Merah di Kabupaten Bangka dengan Menggunakan Metode RSM

ada lagi bagian yang menggumpal. Ini akibat pengaruh pemanasan dan waktu pemanasan yang lebih lama.

\section{KESIMPULAN}

Berdasarkan hasil penelitian diatas dapat disimpulkan bahwa Hasil menunjukan bahwa nilai impak terkecil pada percobaan no 9 yaitu sebesar $264 \mathrm{kj} / \mathrm{m}^{2}$ dengan parameter suhu pemanasan $163,62{ }^{\circ} \mathrm{C}$, waktu $36 \mathrm{Jam}$ dan persentase pasir $10 \%$. dan nilai yang terbesar di percobaan no 10 sebesar $164 \mathrm{kj} / \mathrm{m}^{2}$ dengan parameter suhu pemanasan $836.36{ }^{\circ} \mathrm{C}$, waktu $36 \mathrm{Jam}$ dan persentase pasir $10 \%$. nilai $\mathrm{F}$ hitung FModel = 33,29 yang didapat pada tingkat signifikan sebesar 0,01 atau $1 \%$ dan nilai $p(0,0002)$ memberikan nilai signifikan terhadap model yang ada. Sedangkan Lack of Fit yang terjadi sebesar 0,000199 dan tidak memberikan pengaruh (not signifikan) sehingga persamaan regresi mode matematika dengan bentuk cubic model yang digunakan dapat diterima. Berdasarkan data interaksi dan permukaan respon terhadap kekuatan impak maka pengaruh waktu pemanasan, suhu pemanasan dan persentase pasir sangan besar sekali. Intinya jika suhu dan waktu pemanasan semakin besar maka hasil uji impak semakin besar. hasil SEM diatas untuk Gambar 9(b) menunjukan ada beberapa bagian yang masih belum sempurna proses pemanasannya sehingga ada bagian tersebut yang menggumpal. Sedangkan Gambar 9(a) Proses pemanasan telah sempurna sehingga tidak ada lagi bagian yang menggumpal. Ini akibat pengaruh pemanasan dan waktu pemanasan yang lebih lama

\section{REFERENSI}

[1] Faisol Khoufi A.S, Oyong Novareza dan Purnomo Budi Santoso, "peningkatan kualitas produk batu bata merah dengan memanfaatkan limbah abu serat sabut kelapa dan abu serbuk gergaji" Prosiding Seminar Nasional Multi Disiplin IImu Unisbank ke -3, 2017, pp. 175-181.

[2] Fernanda A, Iswan dan Setyanto, "Studi Kekuatan Pasangan Batu Bata Pasca Pembakaran Menggunakan Bahan Additive Zeolit," JRSDD, vol. 1, no. 1, pp. 371-381, 2012.

[3] Mulyati S.S, Pujiono, Prijanto T.P, Fikri F, "Analisis Kualitas Batu-bata Bersumber Bahan Tambahan Sampah Serbuk Gergaji dalam Berbagai Variasi Berat," Jurnal Kesehatan Lingkungan Indonesia (JKLI), vol. 16, no. 2, pp. 46-50, 2017.

[4] Indra, A. "Kuat Tekan (Compression Strength) Komposit Lempung/Pasir pada Aplikasi Bata Merah Daerah Payakumbuh Sumbar". Jurnal Teknik Mesin, Vol.1, No. 2, pp. 189197, 2012

[5] Azmeri, Devi Sundary, Diana Sapha," Kajian Kualitas Batu Bata Merah Melalui Pemanfaatan Bahan Sedimentasi", Jurnal Teknik Sipil Universitas Syiah Kuala, Vol. 6, No.2, pp. 115-122, 2017

[6] Oscar Fitrah Nur, "Analisa Sifat Fisis dan Mekanis Batu Bata Berdasrkan Sumber Lokasi dan posisi Batu Bata Dalam Proses Pembakaran", Jurnal Rekayasa Sipil (JRS), Universitas Andalas. Vol 2, No.1, pp 85-90, 2008

[7] Standar Nasional Indonesia, SNI 15-2094-2000: Mutu dan Cara Uji Bata Merah Pejal, Departermen Pemukiman dan Prasarana Wilayah. Bandung, 2000.

[8] Wisnu Murtini, "Struktur Dinding Pasangan Batu Merah Lokal Dengan Perkuatan Bilah Bambu Di Daerah Rawan Gempa," Universitas Brawijaya. Malang, 2013

[9] Chritiawan, Ceno Darwanto, "Perilaku Bahan Bata Merah Bersrat Abu Sekam Padi", Program Diploma III T.Sipil Universitas Diponegoro, 2013. 